\title{
La exclusión de la población con discapacidad en España. Estudio específico a partir de la Encuesta Social Europea
}

Social exclusion of people with disabilities in Spain. Specific study from European Social Survey

\section{Resumen}

La discapacidad es una de las fuentes de discriminación más extendidas en la sociedad actual, reconocida con frecuencia por casi medio millón de personas en España, según cifras recientes. La discriminación, como hecho que se produce en la interacción entre personas, es percibida fundamentalmente en escenarios de la vida cotidiana. A partir de un planteamiento operativo de Exclusión Social propuesto por Laparra et al. (2007), y utilizando como fuente de datos principal la Encuesta Social Europea (20IO), se presentan evidencias de discriminación de la población con discapacidad en España en los ejes económico, político-social y de relaciones sociales, en comparación con la población general.

Palabras clave

Discapacidad, exclusión social.

\begin{abstract}
Disability is one of the most widespread causes of discrimination in today's society, often recognized for almost half a million people in Spain, according to recent figures. Discrimination for disability cause, occurs in the interaction between people, and is seen primarily in everyday life scenarios. From an operational of social exclusion approach proposed by Laparra et al. (2007), and using as primary data source the European Social Survey (20I0), evidences of discrimination against people with disabilities in Spain are presented, on economic field, social political and social relations, compared with general population.
\end{abstract}

\section{Keywords}

Disability, social exclusion.

\section{Agustín Huete García <ahueteg@usal.es> \\ Universidad de Salamanca}

\author{
Para citar: \\ Huete García, A. (20I3): "La exclusión \\ de la población con discapacidad en \\ España. Estudio específico a partir de \\ la Encuesta Social Europea”. Revista \\ Española de Discapacidad, I (2): 7-24. \\ $<$ http://dx.doi.org/IO.5569/2340- \\ 5IO4.OI.02.OI>
}

Fecha de recepción: 26-II-2OI2 Fecha de aceptación: I 8-II-20I3 


\section{Introducción}

Existe cierto acuerdo entre expertos e instituciones por el cual se puede definir la Exclusión Social como un proceso, en el que los individuos pueden verse implicados de forma temporal o permanente (Renes, 2009). La concepción de la exclusión social como proceso es especialmente constatable en el momento actual, en el que se cuentan por cientos de miles las personas u hogares que, como consecuencia de la crisis económica, han accedido a una situación de exclusión social. Este consenso se extiende en torno al papel clave que juegan tres zonas o áreas: el mercado laboral, las formas de convivencia y el alcance del "estado del bienestar” (Taylor-Gooby, 2005).

Amartya Sen (2000) añade al concepto de privación un elemento que en relación con la población con discapacidad resultará definitivo: la pobreza medida en función no sólo de elementos económicos, sino relacionales. Esta óptica, supera los análisis tradicionales vinculados exclusivamente a valoraciones económicas para concebir la pobreza como un "fracaso de las capacidades básicas para alcanzar niveles de funcionamiento mínimamente aceptables” (Lépore, 2006: 6).

La sexta edición del VI Informe sobre exclusión $y$ desarrollo social en España (FOESSA, 2008) confirma que, a pesar de la complejidad y el carácter dinámico del fenómeno de la exclusión social, éste incluye dificultades o barreras en al menos el eje económico (empleo, ingresos, privación), el eje político de la ciudadanía (derechos políticos, educación, vivienda o salud) y el eje de las relaciones sociales (aislamiento, desestructuración familiar).

El planteamiento conceptual del VI Informe sobre Exclusión social de la Fundación FOESSA, es el resultado de un gran acuerdo científicooperativo entre los principales estudiosos del fenómeno de la exclusión social en España, que tuvo su plasmación en el documento: Una propuesta de consenso sobre el concepto de exclusión. Implicaciones metodológicas. (Laparra et al., 2007).

La exclusión es entendida entonces, como un fenómeno de causas estructurales cuyo análisis debe centrarse en determinar el impacto de estos

Cuadro 1. Esquema conceptual sobre exclusión social

\begin{tabular}{|l|l|l|}
\hline Ejes de exclusión & Dimensiones & Aspectos \\
\hline \multirow{4}{*}{ Económico } & 1. Participación en la producción & Empleo \\
\cline { 2 - 3 } & \multirow{2}{*}{ 2. Participación del producto social } & Ingresos \\
\cline { 2 - 3 } & 3. Participación política & Privación \\
\cline { 2 - 3 } Político y social (ciudadanía) & 4. Educación & Participación política \\
\cline { 2 - 3 } & 5. Vivienda & Educación \\
\cline { 2 - 3 } & 6. Salud & Vivienda \\
\hline \multirow{4}{*}{$\begin{array}{l}\text { Lazos sociales, relaciones } \\
\text { sociales }\end{array}$} & \multirow{3}{*}{ 7. Conflicto social, anomia } & Conflictos familiares \\
\cline { 2 - 3 } & & Conductas a-sociales \\
\cline { 2 - 3 } & \multirow{3}{*}{ 8. Aislamiento social } & Conductas delictivas \\
\hline & & Sin apoyo familiar \\
\cline { 2 - 3 } & & Conflicto vecinal \\
\cline { 2 - 3 } & & Institucionalizados \\
\hline
\end{tabular}

Fuente: VI Informe sobre Exclusión social en España de la Fundación FOESSA (2008). 
ejes de riesgo sobre los individuos, hogares, comunidades, etc. en un mapa conceptual con las siguientes dimensiones y aspectos:

La discapacidad (como la exclusión social) es en sí misma la representación de un fenómeno complejo, diverso, polémico y multidimensional, que, como tal, presenta dificultades a una sociedad tendente a ofrecer respuestas universales ante las necesidades y demandas de la población.

Al contrario que ocurre con la exclusión social, la discapacidad como hecho social carece de una identificación conceptual estable, lo cual determina problemas de medición que a veces son graves, ya que no todos los registros y estadísticas denominan los aspectos de la discapacidad con los mismos conceptos, y por tanto miden cosas diferentes, o viceversa, miden los mismos fenómenos con categorías diferentes (Jiménez y Huete, 2010).

La discapacidad es, además, un fenómeno disperso en la población general, por lo que la toma de datos resulta extraordinariamente dificultosa. Tal como reconoce CERMI (2003: 56): "A pesar del aumento de material publicado sobre estudios comparativos en el campo de la discapacidad, existe una considerable falta de estadísticas comparativas sobre las condiciones de vida de las personas con discapacidad, la discriminación sistemática y las barreras a las que se enfrentan en su entorno económico y social".

En este artículo se pretende identificar escenarios en los que las personas con discapacidad se enfrentan a exclusión social, en comparación con la población general. Para ello se plantea una estrategia metodológica basada en técnicas de investigación cuantitativa.

A partir de fuentes de datos disponibles en la actualidad se tratará de presentar comparativamente y con evidencia estadística las diferencias que existen en términos de exclusión social de la población con discapacidad, utilizando como referencia la población general. Para evidenciar la situación objetiva de discriminación de la población con discapacidad en determinados escenarios, resulta preciso utilizar un grupo poblacional estándar que ejerza de alguna manera como "grupo de control" y nos ayude a tomar una referencia clara de hasta qué punto la condición de discapacidad plantea diferencias en términos de exclusión social. Para alcanzar este objetivo, se utilizará una fuente de datos común a la población con discapacidad y la población general.

\section{Metodología}

La Convención Internacional sobre los Derechos de las Personas con Discapacidad, contempla en su artículo 3I -dedicado a la "Recopilación de datos y estadísticas"- que "los Estados Partes recopilarán información adecuada, incluidos datos estadísticos y de investigación, que les permita formular y aplicar políticas, a fin de dar efecto a la presente Convención" (ONU, 2006).

En general, las principales limitaciones que se encuentran en las referencias estadísticas actuales tienen que ver con la ausencia de cualquier tratamiento de las situaciones de discapacidad (Jiménez y Huete, 20I0). Tomando como referencia el Instituto Nacional de Estadística, de las 2 I 3 operaciones estadísticas disponibles en su Base de Datos, I84 no hacen referencia alguna a las situaciones de discapacidad, 26 realizan algún tipo de alusión indirecta a esta cuestión y tan sólo en 4 de ellas, se hace algún tipo de referencia específica sobre discapacidad (Huete y Quezada, 20I2).

La Encuesta sobre Discapacidad, Autonomía personal y situaciones de Dependencia (EDAD 2008) es la tercera de una serie de estadísticas que comenzó en I986 con la Encuesta sobre Discapacidades, Deficiencias y Minusvalías (EDDM I986) y continuó con la Encuesta sobre Discapacidades, Deficiencias y Estado de Salud (EDDS I999).

Existen otras fuentes estadísticas importantes procedentes tanto del INE como de otros 
organismos que tratan la discapacidad en diferentes ámbitos. Sin embargo, el uso que se ha realizado de estos recursos para análisis sociales es relativamente escaso.

Aunque intuitivamente una buena opción para conocer las situaciones de discriminación de la población con discapacidad sería acudir a las fuentes que se han dedicado al estudio de la exclusión social, la pobreza o la desigualdad, éstas por lo general no han reparado en la toma de datos sobre la situación de discapacidad de la población a la que se han dirigido, o lo han hecho de una manera indirecta. Este es el caso, por ejemplo, del Panel de Hogares de la Unión Europea (PHOGUE) o de la Encuesta de Condiciones de Vida (ECV), operación que ha sustituido al POGHUE, que se realiza anualmente desde 2004 y que también es una operación armonizada para los países de la Unión Europea. Pese a que en la concepción metodológica de ambas encuestas sí se tienen en cuenta variables relacionadas con discapacidad, éstas no permiten realizar un uso suficientemente fiable (Huete y Quezada, 20I2).

La Encuesta Social Europea (de ahora en adelante, ESE) es un estudio comparado y longitudinal que se lleva a cabo cada dos años, en el que participan alrededor de 30 países europeos. Tiene como principal objetivo analizar el cambio y la continuidad de las actitudes, atributos y comportamientos sociales y políticos de los ciudadanos europeos. La ESE está promovida por la European Science Foundation y cuenta con el apoyo de distintas instituciones públicas europeas y españolas, entre las que se encuentra el CIS. La ESE permite identificar a la población con discapacidad, aunque presenta un problema de fiabilidad para análisis complejos, ya que la base muestral de personas con discapacidad para su edición de 20 Io es de 286 casos.

La ESE es en la actualidad una de las escasas fuentes estadísticas que, aplicadas a población general, permite identificar y extraer información comparativa sobre la población con discapacidad. Es por ello que constituye la principal fuente de información de este artículo.

\subsection{Planteamiento operativo}

El planteamiento operativo de este trabajo parte del consenso sobre Exclusión Social (Laparra et al., 2007), que ha servicio como sustrato a diferentes análisis recientes en España. Como fuente de datos principal, se utilizará la ESE, que permite en cierta forma identificar las situaciones de discapacidad, de las personas que han participado.

Una vez identificado el modelo analítico a utilizar, las dimensiones seleccionadas, y la fuente de información disponible, es posible presentar de una manera esquemática, una serie de indicadores que respondan a los conceptos planteados y estén disponibles en la fuente a utilizar (ESE). Tal como se muestra a continuación, se han seleccionado 5 indicadores para cada dimensión propuesta (Cuadro 2).

\subsection{Preparación de datos}

Originalmente, la muestra total de la ESE para España estaba constituida por I.599 casos, de los que 286 reconocen discapacidad. La distribución por grandes grupos de edad era muy desigual entre las dos submuestras (personas con y sin discapacidad), por lo que ha sido preciso realizar una reconstrucción de la submuestra de uno de los dos grupos. Dado que el grupo de personas con discapacidad era el menos numeroso, se ha procedido a seleccionar aleatoriamente casos de la muestra de personas sin discapacidad, hasta obtener dos muestras homogéneas por grandes grupos de edad. El resultado es el siguiente (Tabla I).

\section{Resultados}

A partir de los datos de la Encuesta Social Europea (20I0), se han identificado I 5 indicadores relacionados con tres grandes áreas en las que es posible encontrar evidencias de exclusión social de las personas con 


\section{Cuadro 2. Indicadores sobre exclusión seleccionados}

\begin{tabular}{|c|c|c|}
\hline $\begin{array}{l}\text { Ejes de } \\
\text { exclusión }\end{array}$ & Dimensiones & Indicadores en la Encuesta Social Europea (2010) \\
\hline \multirow{5}{*}{ Económico } & \multirow{5}{*}{$\begin{array}{l}\text { Acceso a } \\
\text { empleo e } \\
\text { ingresos }\end{array}$} & Alguna vez ha tenido un trabajo remunerado \\
\hline & & Actividad principal en los siete días anteriores \\
\hline & & Ingresos del hogar \\
\hline & & Percepción de dificultades con los ingresos del hogar actuales \\
\hline & & $\begin{array}{l}\text { Facilidad para pedir ayuda económica en su entorno para llegar a fin de } \\
\text { mes, si fuera preciso }\end{array}$ \\
\hline \multirow{5}{*}{$\begin{array}{l}\text { Político } \\
\text { y social } \\
\text { (ciudadanía) }\end{array}$} & \multirow{5}{*}{$\begin{array}{l}\text { Educación, } \\
\text { Salud, } \\
\text { Participación }\end{array}$} & Nivel de estudios más alto alcanzado \\
\hline & & Satisfacción con la vida \\
\hline & & Auto-percepción del estado de salud (estado de salud percibido) \\
\hline & & Toma parte en actividades sociales en comparación con otras personas \\
\hline & & Interés por asuntos políticos \\
\hline \multirow{5}{*}{ Lazos sociales } & \multirow{5}{*}{$\begin{array}{l}\text { Aislamiento, } \\
\text { Violencia }\end{array}$} & Frecuencia con la que trata con amigos o familiares \\
\hline & & Cuánto tiempo se ha sentido solo durante la última semana \\
\hline & & Se puede confiar en la mayoría de la gente \\
\hline & & Las personas tratan de aprovecharse de mí \\
\hline & & Frecuencia con que le preocupa ser víctima de un delito violento \\
\hline
\end{tabular}

Fuente: Elaboración propia a partir de Laparra, M. et al. (2007) y Encuesta Social Europea (ESE, 20IO).

Tabla 1. Encuesta Social Europea: Resumen de selección de casos de la muestra

\begin{tabular}{|l|c|c|c|}
\hline & $\begin{array}{c}\text { Muestra de personas sin } \\
\text { discapacidad original }\end{array}$ & $\begin{array}{c}\text { Muestra de personas sin } \\
\text { discapacidad seleccionada }\end{array}$ & $\begin{array}{c}\text { Muestra de } \\
\text { personas con } \\
\text { discapacidad }\end{array}$ \\
\hline \multicolumn{5}{|c|}{ Total muestra (y porcentaje) } \\
\hline Menores de 65 años & $1.402(87,93 \%)$ & $172(46,61 \%)$ & $134(46,85 \%)$ \\
\hline 65 o más años & $197(12,07 \%)$ & $197(53,39 \%)$ & $152(53,15 \%)$ \\
\hline Muestra Total & $\mathbf{1 . 5 9 9 ( 1 0 0 , 0 0 \% )}$ & $\mathbf{3 6 9 ( 1 0 0 , 0 0 \% )}$ & $\mathbf{2 8 6}(\mathbf{1 0 0 , 0 0 \% )}$ \\
\hline Margen de error $\left(^{*}\right)$ & $\mathbf{2 , 4 5 \%}$ & $\mathbf{5 , 1 \%}$ & $\mathbf{5 , 7 9 \%}$ \\
\hline
\end{tabular}

(*) Para un Nivel de Confianza del 95,5\% y una Varianza Poblacional $\mathrm{P}=\mathrm{Q}=50$ Fuente: Elaboración propia. 
discapacidad. A través de pruebas de análisis estadístico (ANOVA de un factor) se han evidenciado diferencias significativas entre población con discapacidad y población general en todos los indicadores propuestos, para cada una de las tres ejes clave: económico, participación social y relaciones sociales, tal como se resumen en la Tabla 2.

\subsection{Eje económico}

La necesidad de abordar la discapacidad como un factor relacionado con la privación económica no es sólo un tema de justicia social. Finalizar con el impacto económico de la discapacidad significaría que más personas podrían incorporarse a una vida activa, aumentando la contribución neta a la Hacienda Pública a través de los impuestos, y reduciendo el número de pensiones adjudicadas por carecer de empleo. En la actualidad, la capacidad de ahorro de las personas con discapacidad es casi inexistente, y ello se debe a múltiples factores relacionados con el sobrecoste de la discapacidad, así como las menores oportunidades de acceso a recursos y generación de ingresos.

Además de tener ingresos menores, las personas con discapacidad asumen unos costes extraordinarios en su vida diaria, lo cual incide negativamente en su calidad de vida. Según estudios recientes - si se tienen en cuenta estos costes extraordinarios- el número de personas con discapacidad que viven por debajo del umbral de la pobreza en el mundo pasa del $30 \%$ a ser más del $50 \%$. La renta de las personas con discapacidad se encuentra por debajo de la renta media de la población general en un $40 \%$ (Zaidi y Burchardt, 2003).

\section{Tabla 2. ANOVA de un factor sobre indicadores relacionados con excusión social, entre población con y sin discapacidad}

\begin{tabular}{|c|c|c|c|}
\hline Eje & Indicadores & $\mathbf{F}$ & Sig. \\
\hline \multirow{5}{*}{ Económico } & 1. Alguna vez ha tenido un trabajo remunerado & 9,783 & 0,002 \\
\hline & 2. Actividad principal en los siete días anteriores & 30,802 & 0,000 \\
\hline & 3. Ingresos del hogar & 15,806 & 0,000 \\
\hline & 4. Percepción de dificultades con los ingresos del hogar actuales & 37,836 & 0,000 \\
\hline & $\begin{array}{l}\text { 5. Facilidad para pedir ayuda económica en su entorno para llegar a } \\
\text { fin de mes, si fuera preciso }\end{array}$ & 11,905 & 0,001 \\
\hline \multirow{5}{*}{$\begin{array}{l}\text { Político } \\
\text { y social } \\
\text { (ciudadanía) }\end{array}$} & 6. Nivel de estudios más alto alcanzado & 13,520 & 0,000 \\
\hline & 7. Satisfacción con la vida & 41,925 & 0,000 \\
\hline & 8. Auto-percepción del estado de salud (estado de salud percibido) & 395,860 & 0,000 \\
\hline & $\begin{array}{l}\text { 9. Toma parte en actividades sociales en comparación con otras } \\
\text { personas }\end{array}$ & 32,039 & 0,000 \\
\hline & 10. Interés por asuntos políticos & 9,724 & 0,002 \\
\hline \multirow{5}{*}{$\begin{array}{l}\text { Lazos } \\
\text { sociales }\end{array}$} & 11. Frecuencia con la que trata con amigos o familiares & 6,015 & 0,014 \\
\hline & 12. Cuánto tiempo se ha sentido solo durante la última semana & 34,232 & 0,000 \\
\hline & 13. Se puede confiar en la mayoría de la gente & 7,629 & 0,006 \\
\hline & 14. Las personas tratan de aprovecharse de mí & 11,260 & 0,001 \\
\hline & 15. Frecuencia con que le preocupa ser víctima de un delito violento & 8,290 & 0,004 \\
\hline
\end{tabular}

Fuente: Elaboración propia a partir de la Encuesta Social Europea (2010). 
En España en 2008, más de un millón y medio de personas con discapacidad (I.525.867 en total) se encontraban en situación de pobreza de las que casi medio millón se situaban bajo el umbral de pobreza extrema. En términos relativos, el $\mathrm{I} 7,3 \%$ de las mujeres con discapacidad se encontraba en situación de pobreza extrema, tasa que triplicaba la de la población española $(6,4 \%)$ en 2008 y era sensiblemente superior a la de los varones con discapacidad ( I I \%). Aproximadamente la mitad de la población con discapacidad se encuentra por encima de los límites de riesgo de pobreza $(48,4 \%)$, proporción que asciende a casi tres cuartas partes en la población general (74\%) (Huete, 20I3).

La situación laboral resulta un indicador esencial de calidad de vida y la carencia de empleo es uno de los principales indicadores

Gráfico 1. Población con y sin discapacidad, que alguna vez ha tenido un trabajo remunerado. 2010. Porcentajes

$\begin{array}{r}100 \\ \hline 90 \\ \hline 80 \\ \hline 70 \\ \hline 60 \\ \hline 50 \\ \hline 40 \\ \hline 30 \\ \hline 20 \\ \hline 10 \\ \hline 0\end{array}$

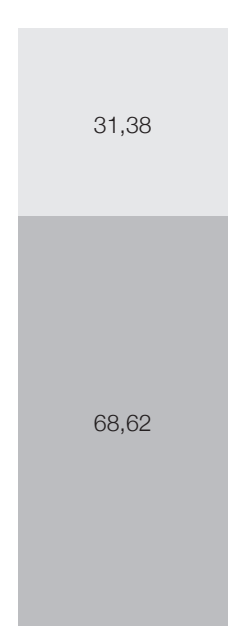

Con discapacidad

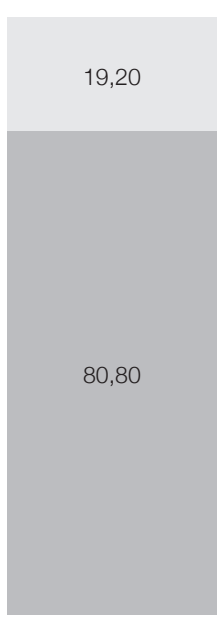

Sin discapacidad

\section{No}

Sí

Fuente: Elaboración propia a partir de la Encuesta Social Europea (ESE, 20IO). de exclusión social, dada la posición central del empleo en la vida personal y social del individuo. Las transformaciones del mercado laboral durante las últimas décadas lo han fragmentado incrementando su flexibilidad, como un elemento característico del empleo (Subirats, 2005). Es precisamente el grupo de personas con discapacidad uno de los que presenta mayores obstáculos a la hora de acceder al mercado laboral.

A través de pruebas de análisis estadístico (ANOVA de un factor) se han evidenciado diferencias significativas entre población con discapacidad y población general en dos elementos clave: el acceso al trabajo remunerado y la actividad principal que realizan (Tabla 2). Existe una diferencia porcentual de más de I 2 puntos entre la población con y sin discapacidad que alguna vez ha tenido un trabajo remunerado

\section{Gráfico 2. Población con y sin discapacidad en edad laboral, según actividad en la última semana, 2010. Porcentajes}

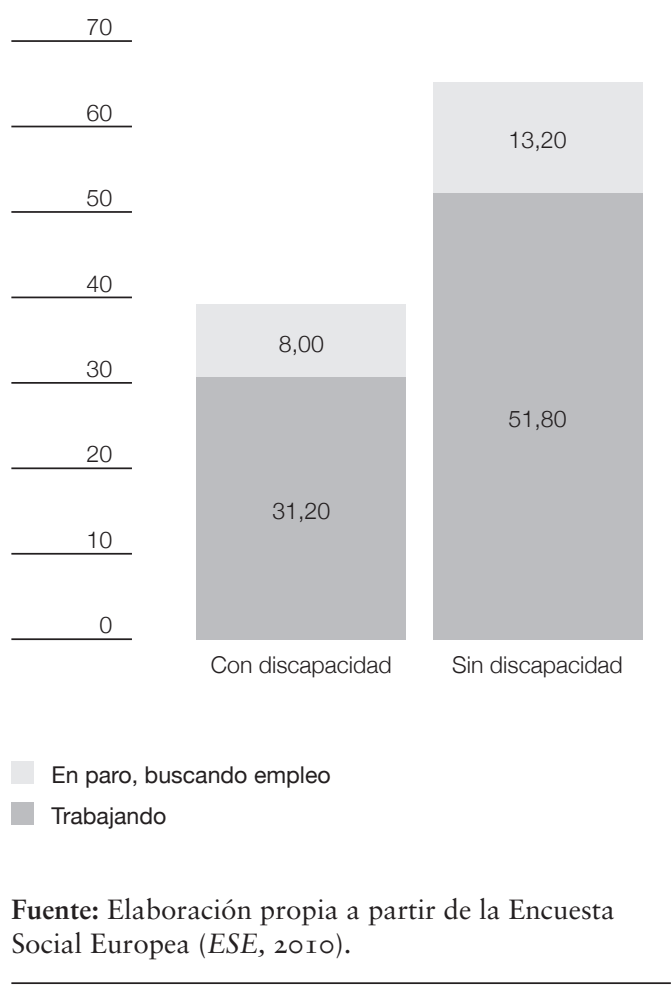


(68,62 \% frente a $80,80 \%$ respectivamente). La población en edad laboral que efectivamente está trabajando es apenas un tercio en el caso de las personas con discapacidad, por más de la mitad en el resto de la población.

A partir de los datos de la ESE, se han encontrado diferencias significativas entre la población con y sin discapacidad en relación con los ingresos del hogar (Tabla 2). La población con discapacidad tiene un perfil comparativamente más desfavorable, en cuanto a los ingresos netos (que resultan inferiores), así como en la capacidad para afrontar situaciones de dificultad en este ámbito.

Los hogares en los que viven personas con discapacidad presentan un nivel medio de

\section{Gráfico 3. Población con y sin discapacidad} según ingresos del hogar, 2010. Porcentajes

$\begin{array}{r}100 \\ \hline 90 \\ \hline 80 \\ \hline 70 \\ \hline 60 \\ \hline 50 \\ \hline 40 \\ \hline 30 \\ \hline 20 \\ \hline 10 \\ \hline 0 \\ \hline\end{array}$

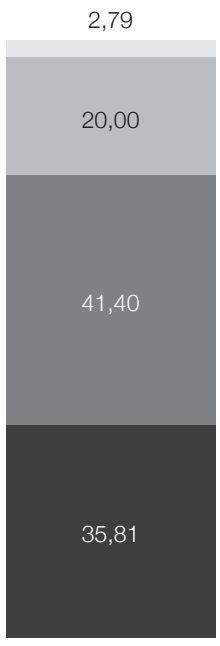

Con discapacidad

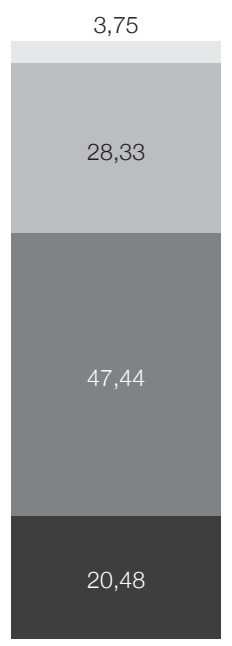

Sin discapacidad
Más de $3.500 €$

] $1.701 €$ a $3.500 €$

$901 € a 1.700 €$

$900 €$ o menos

Fuente: Elaboración propia a partir de la Encuesta Social Europea (ESE, 20IO). ingresos sistemáticamente inferior que los hogares en los que no viven personas con discapacidad. Las diferencias además, son más notables en los hogares en los que los ingresos son más bajos: un 35,8 I \% de la población con discapacidad vive en hogares con ingresos iguales o inferiores a 900 euros, frente al $20,48 \%$ en la población general.

La población con discapacidad que reconoce dificultades para llegar a fin de mes es prácticamente el doble que en la población general (36,I4\% frente al I9,I3 \%), situación que se agrava por la disponibilidad de redes en el entorno en las que poder encontrar algún soporte económico, soporte difícil para casi tres cuartas partes de la población con discapacidad $(72,53 \%)$.

\section{Gráfico 4. Población con y sin discapacidad según percepción respecto a los ingresos de su hogar en la actualidad, 2010. Porcentajes}
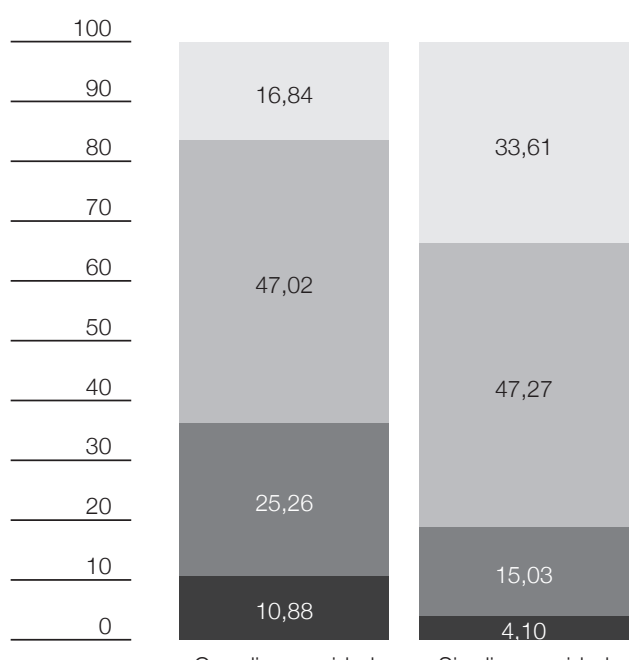

Con discapacidad

Sin discapacidad
Con los ingresos actuales nos llega para vivir
Con los ingresos actuales tenemos dificultades
Con los ingresos actuales tenemos muchas dificultades

Fuente: Elaboración propia a partir de la Encuesta Social Europea (ESE, 20IO). 


\section{Gráfico 5. Población con y sin discapacidad según facilidad para pedir ayuda económica en su entorno para llegar a fin de mes, si fuera preciso, 2010. Porcentajes}

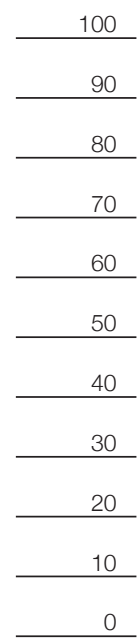

Sin dificultad

Con dificultad

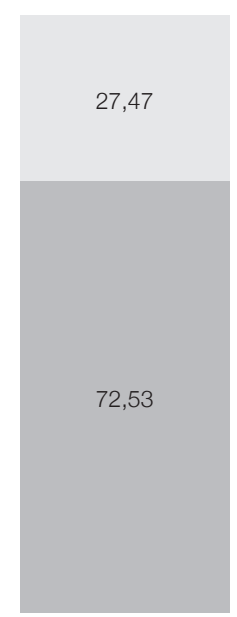

Con discapacidad

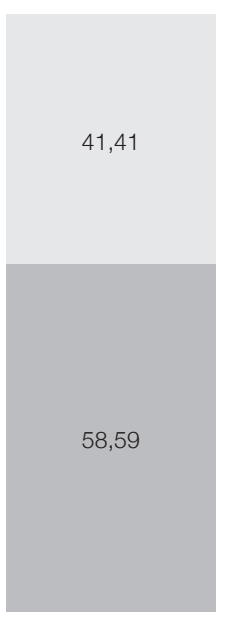

Sin discapacidad
Fuente: Elaboración propia a partir de la Encuesta Social Europea (ESE, 2010).

\subsection{Eje político y social (ciudadanía)}

Dado que la discapacidad puede y debe ser considerada como un fenómeno fundamentalmente social, y quizá por ello, es preciso atender a los recursos con que las personas con discapacidad cuentan para ejercer sus derechos reconocidos a la participación social. Cualquier ejemplo de discriminación en este ámbito, determinará el resultado en términos de exclusión social de la población con discapacidad.

La ESE muestra diferencias estadísticamente significativas entre población general y población con discapacidad, en ámbitos clave relacionados con la participación social, como son el acceso a estudios, cuidado de la salud, o el interés por actividades sociales y asuntos políticos. En todos ellos, han resultado significativas las diferencias entre los grupos poblacionales con y sin discapacidad (Tabla 2).

La educación constituye un elemento clave en el desarrollo personal y profesional de un individuo y un ámbito en el que tradicionalmente se ha distinguido claramente la discriminación hacia las personas con discapacidad, tal como se reconoce en la Convención Internacional sobre los Derechos de las Personas con Discapacidad en su artículo 24, dedicado plenamente a la educación (ONU, 2006).

Las cifras disponibles sobre acceso a la educación de las personas con discapacidad muestran que la tasa de analfabetismo entre las personas con discapacidad, incluso aquellas que no presentan dificultades para el aprendizaje, es muy superior a las de la población general (Huete, 20I3:57).

\section{Gráfico 6. Población con y sin discapacidad según nivel de estudios alcanzados, 2010. Porcentajes}

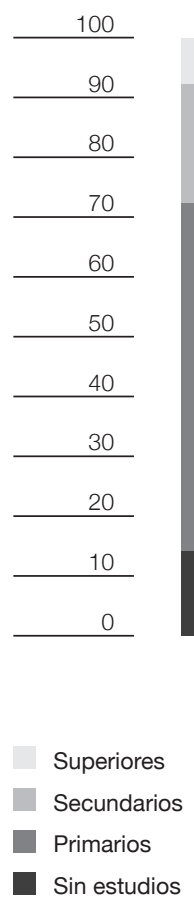

Fuente: Elaboración propia a partir de la Encuesta Social Europea (ESE, 20Io). 
A partir de una escala en la que o indica completa infelicidad y ro felicidad completa, la población con discapacidad presenta puntuaciones inferiores a la población sin discapacidad, en cuanto a satisfacción con la vida, de forma sistemática. Como promedio, la población con discapacidad puntúa 5,99, frente al 6,84.

La sociedad moderna ha reconocido la salud como un derecho fundamental, y se ha definido el derecho a la asistencia sanitaria expresado en el mantenimiento de la salud y el derecho a recuperarla en caso de enfermedad. Dentro del marco del bienestar personal y social, la salud constituye un pilar básico en una sociedad desarrollada, ya que otorga alternativas de acción a la ciudadanía para una mayor participación y autonomía. Tal como indica Subirats (2004) la salud es un ámbito donde las desigualdades sociales se manifiestan con mayor fuerza.

Existen diferencias relevantes en elementos relacionados con salud, en los que la población con discapacidad presenta resultados desfavorables en comparación con la población general (Tabla 2). Más de la mitad de la población con discapacidad reconoce un estado de salud subjetivo malo o muy malo, frente a menos del $6 \%$ en la población general.

Se han encontrado evidencias estadísticamente significativas, según las cuales la población con discapacidad accede de manera menos frecuente a escenarios de participación social, tales como la participación en actividades sociales y el interés en asuntos políticos (Tabla 2).

Más de la mitad de la población con discapacidad reconoce participar en actividades sociales en menor medida que otras personas de su entorno, frente a un tercio de la población general que reconoce una situación similar. Más del $40 \%$ de las personas con discapacidad, sin embargo, reconoce tener ningún interés por asuntos políticos, por un $30 \%$ de la población general.

\section{Gráfico 7. Población con y sin discapacidad según auto percepción de satisfacción con la vida (Escala 0 a 10), 2010. Porcentajes}

35,0

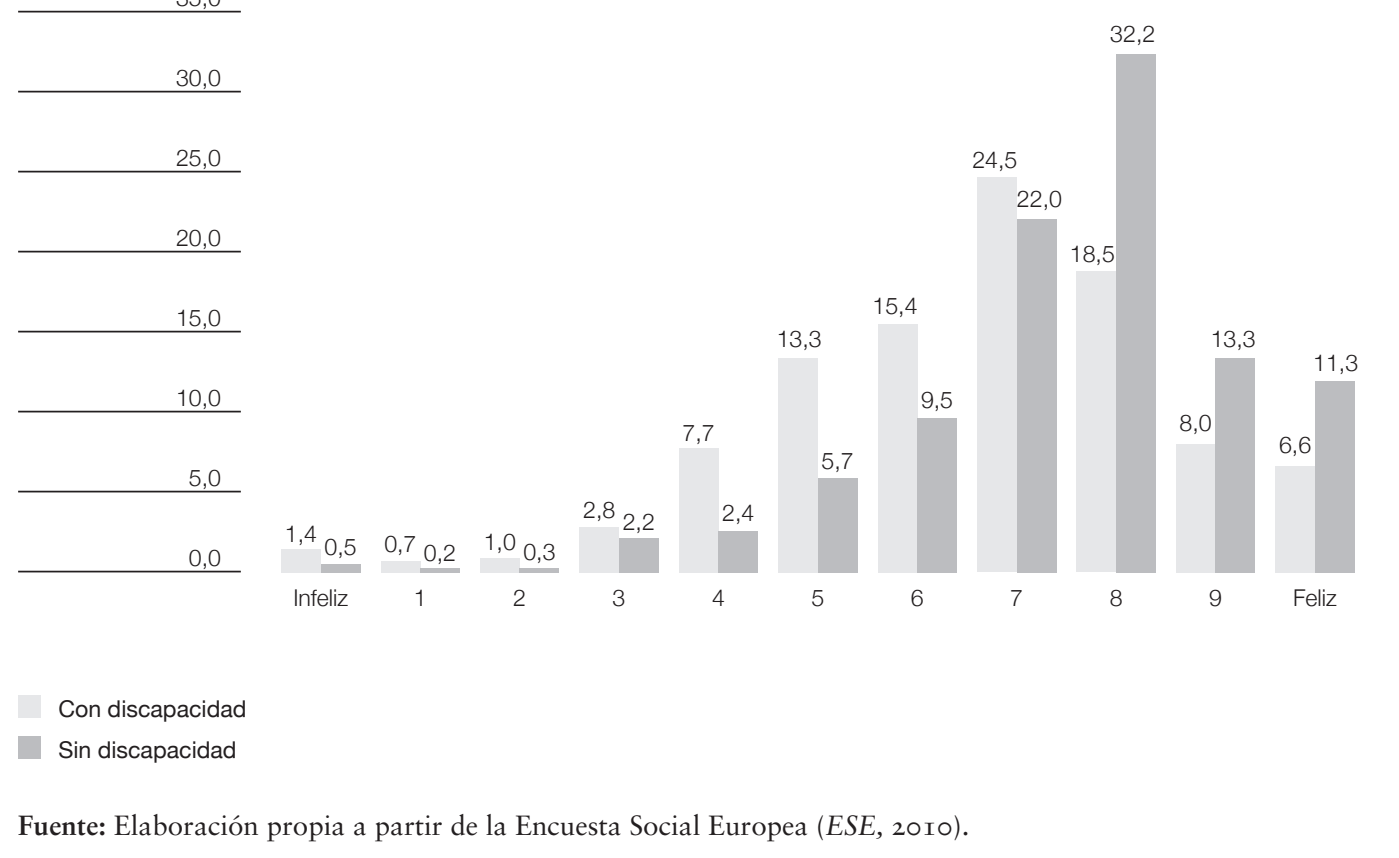


Gráfico 8. Población con y sin discapacidad según estado de salud percibido, 2010. Porcentajes

$\begin{array}{r}100 \\ \hline 90 \\ \hline 80 \\ \hline 70 \\ \hline 60 \\ \hline 50 \\ \hline 40 \\ \hline 30 \\ \hline 20 \\ \hline 10 \\ \hline 0\end{array}$

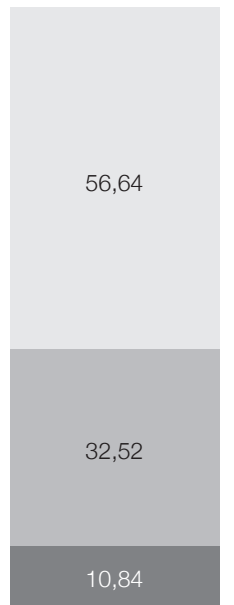

Con discapacidad

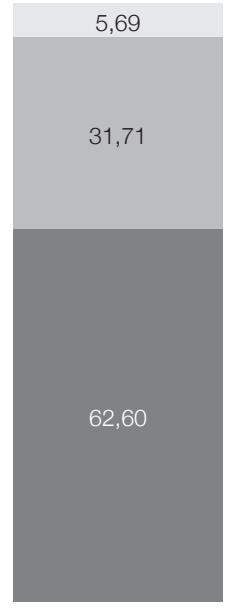

Sin discapacidad
Malo o muy malo

Normal

Bueno o muy bueno

Fuente: Elaboración propia a partir de la Encuesta Social Europea (ESE, 20IO).
Gráfico 9. Población con y sin discapacidad según frecuencia con que toma parte en actividades sociales en comparación con los demás, 2010. Porcentajes

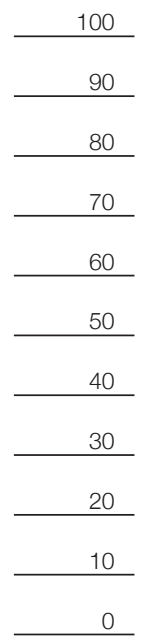

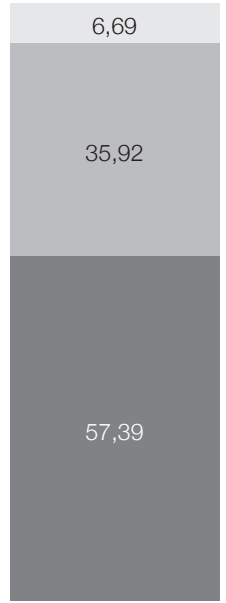

Con discapacidad
7,07

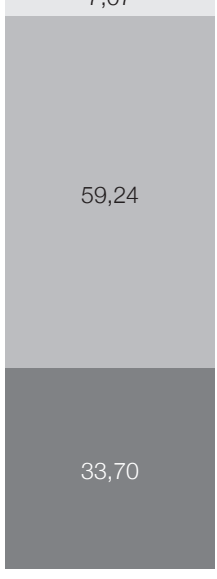

Sin discapacidad
Más que los demás

- Igual que los demás

Menos que los demás

Fuente: Elaboración propia a partir de la Encuesta Social Europea (ESE, 20IO).

\section{Gráfico 10. Población con y sin discapacidad según interés por asuntos políticos, 2010. Porcentajes}

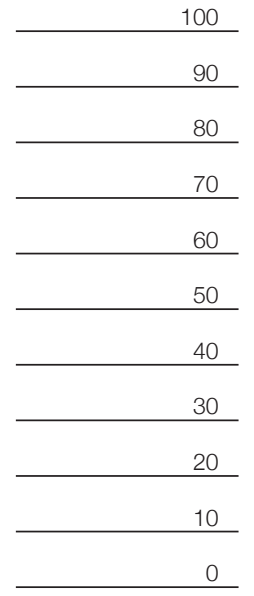

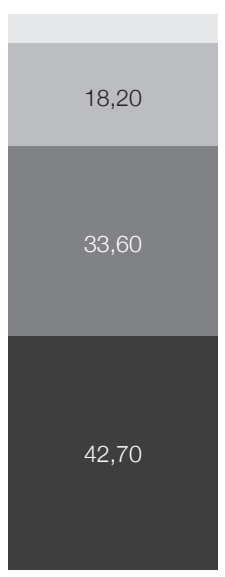

Con discapacidad

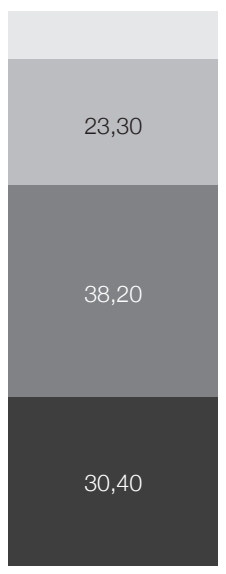

Sin discapacidad

\author{
Muy interesado \\ Bastante interesado \\ Poco interesado
}

Nada interesado

Fuente: Elaboración propia a partir de la Encuesta Social Europea (ESE, 20Io). 


\subsection{Lazos sociales, relaciones sociales}

La importancia y necesidad del desarrollo de las relaciones sociales supone un aspecto fundamental en las personas con discapacidad, no sólo por una cuestión social, sino también para el desarrollo de la personalidad y estabilidad emocional. Situaciones de excesiva dependencia familiar, falta de privacidad o intimidad, sumadas a un entorno familiar con una economía escasa suponen para las personas con discapacidad graves dificultades a la hora de desarrollar, iniciar o mantener relaciones sociales de todo tipo (de amistad, de compañerismo, de pareja, etc.).

La ansiedad y el estrés producidos por una sensación persistente de inferioridad producen problemas en la autoestima. La autoestima constituye un aspecto básico en el desarrollo integral de cualquier individuo, en particular en el aspecto emocional ya que, cuando existe una aceptación importante de sí mismo, se experimenta una mejor calidad de vida. El apoyo social es el mediador social más importante para la ansiedad y el estrés, porque amortigua sus efectos. El soporte social incluye a parientes, conocidos, amigos, personas significativas e individuos vinculados a servicios de atención con los que se adoptan relaciones de confianza. Esta red de relaciones sociales influye sobre el desarrollo y bienestar personal y psicosocial de las personas en general, y de las personas con discapacidad en particular (Fernández, 20II).

La ESE ofrece información sobre diferentes elementos relacionados con oportunidades para relacionarse con otras personas. En general, los análisis estadísticos muestran que las personas con discapacidad presentan diferencias estadísticamente significativas con la población general en aspectos relacionados con confianza en las personas y preocupación por ser víctima de delitos violentos (Tabla 2).

La frecuencia con que se mantienen relaciones con amigos o familiares resulta un indicador que evidencia claras diferencias, de forma que son casi el doble las personas con discapacidad que reconocen no tener nunca o casi nunca ocasión de tratar a amigos o familiares. En línea con este resultado, son tres veces más las personas con discapacidad que reconocen haberse sentido solas siempre o casi siempre durante la semana anterior a la realización de la encuesta.

\section{Población con y sin discapacidad según frecuencia con la que trata con amigos o familiares, 2010. Porcentajes}

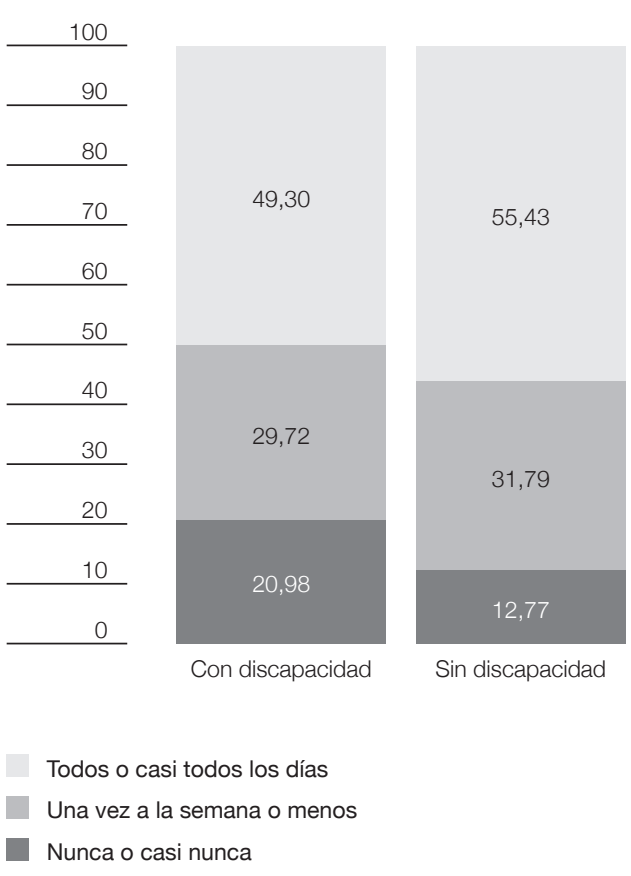

Fuente: Elaboración propia a partir de la Encuesta Social Europea (ESE, 20IO).

En una valoración de indicadores relacionados con la confianza en las personas, la población con discapacidad muestra en general menor tendencia a mostrarse confiada y más preocupada por ser objeto de abuso en el contexto social. Más de un $40 \%$ de las personas con discapacidad reconoce no confiar en la mayoría de la gente, y casi un $35 \%$ cree que en general otras personas pueden intentar aprovecharse de ellas, indicadores que resultan en más de ro puntos porcentuales superiores a los de la población general. 
Gráfico 12. Población con y sin discapacidad según tiempo en que se ha sentido solo durante la última semana, 2010. Porcentajes

$\begin{array}{r}100 \\ \hline 90 \\ \hline 90 \\ \hline 70 \\ \hline 60 \\ \hline 50 \\ \hline 40 \\ \hline 30 \\ \hline 20 \\ \hline 10 \\ \hline 0 \\ \hline\end{array}$

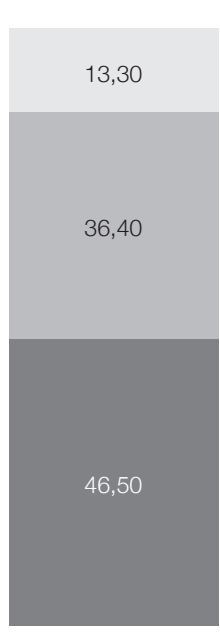

Con discapacidad

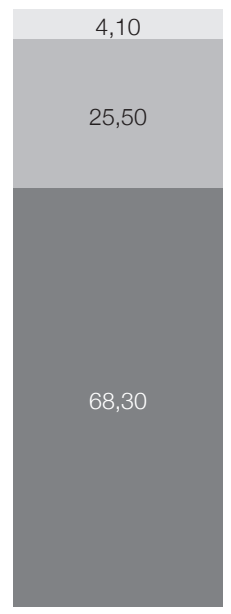

Sin discapacidad

Siempre o casi siempre

Algunas veces

Nunca o casi nunca

Fuente: Elaboración propia a partir de la Encuesta Social Europea (ESE, 20I0).
Gráfico 13. Población con y sin discapacidad según confianza que muestra en las personas, 2010. Porcentajes

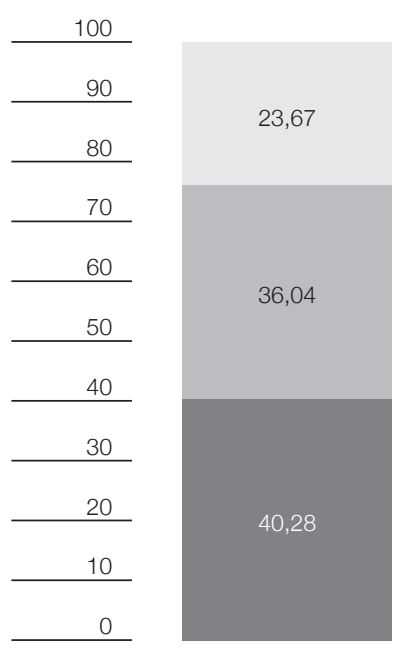

Con discapacidad

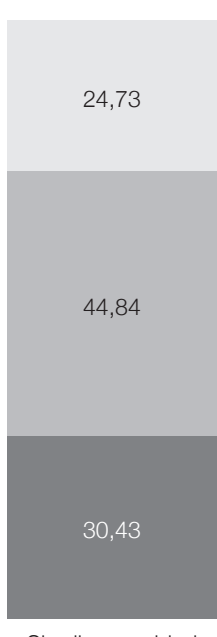

Sin discapacidad
Se puede confiar en la mayoría de la gente

- Sin opinión definida

No se puede confiar en la mayoría de la gente

Fuente: Elaboración propia a partir de la Encuesta Social Europea (ESE, 2010).

Gráfico 14. Población con y sin discapacidad opinión sobre si las personas tratan de aprovecharse de ellas, 2010. Porcentajes

$\begin{array}{r}100 \\ \hline 90 \\ \hline 80 \\ \hline 70 \\ \hline 60 \\ \hline 50 \\ \hline 40 \\ \hline 30 \\ \hline 20 \\ \hline 10 \\ \hline 0 \\ \hline\end{array}$

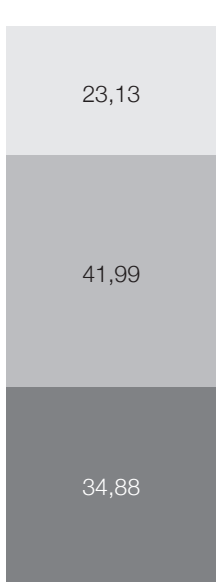

Con discapacidad

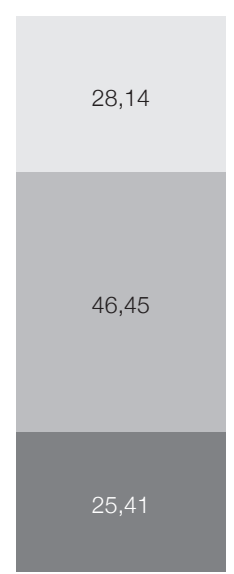

Sin discapacidad
Las personas no tratan de aprovecharse de $\mathrm{m}$ Sin opinión definida

Las personas tratan de aprovecharse de mí

Fuente: Elaboración propia a partir de la Encuesta Social Europea (ESE, 20Io). 
En febrero de 2012 han sido publicados resultados preliminares de la IV Macroencuesta de Violencia de Género 20I I, iniciativa del Instituto de la Mujer en todas sus ediciones (I999, 2002, 2006 y 20II), realizada en 20I I por el CIS. En esta edición se ha contemplado la presencia de alguna enfermedad o discapacidad de las mujeres encuestadas, a pesar de lo cual, los datos disponibles no permiten obtener información sobre el tipo de discapacidad o saber si la violencia ha producido secuelas discapacitantes (Huete y Quezada, 20I2). De acuerdo con los principales resultados, se observa que "la prevalencia de la violencia de género es más elevada entre las mujeres que indican que tienen problemas graves para llevar a cabo sus actividades diarias ( $18,8 \%$ ) y entre las que tienen problemas en cierta medida (I I, $5 \%$ ) que en las que no tienen problemas ( $10,3 \%$ ). El IO,I \% de las que sufrían algún tipo de discapacidad manifestó haber sufrido violencia de género alguna vez en la vida (frente al 6,I \% de las no discapacitadas), y el 4,3\% manifestó haberlo sufrido en el último año (frente al I,9\% de las que no tenían discapacidad)" (MSSSI, 20II).

La ESE ofrece también una serie de indicadores sobre los que se han obtenido diferencias significativas entre la población con discapacidad y el resto de la población, relacionados con la preocupación cotidiana sobre ser víctima de un delito violento, tal como se muestra en la Tabla 2. En general, este tipo de preocupación es significativamente más frecuente entre la población con discapacidad.

\section{Discusión y conclusiones}

Históricamente, las personas con discapacidad han sido etiquetadas, estigmatizadas y colocadas en una posición de inferioridad frente a la sociedad, generando así actitudes de rechazo, y conductas de sobreprotección, lo que ha conducido, por vías diferentes, a un trato de personas incapaces de valerse por sí mismas (Palacios y Bariffi, 2007:I3). Las personas con

\section{Gráfico 15. Población con y sin discapacidad según frecuencia con que le preocupa ser víctima de un delito violento, 2010. Porcentajes}

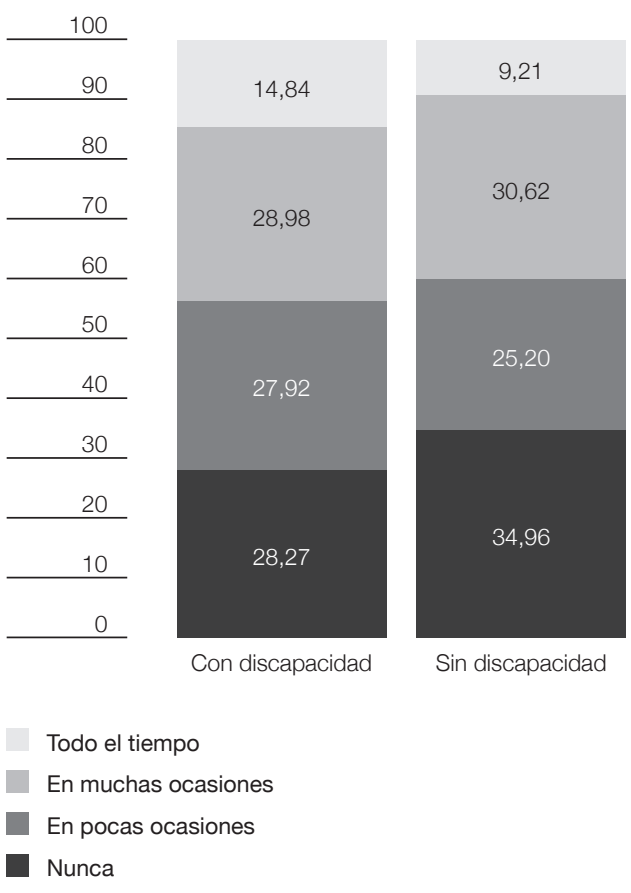

Fuente: Elaboración propia a partir de la Encuesta Social Europea (ESE, 20I0).

discapacidad se han visto así impedidas para ejercer sus derechos resultando, una situación de ciudadanía de "segunda clase".

La discapacidad es en la actualidad un fenómeno crecientemente concebido como resultado de la desventaja a la hora de participar en igualdad de oportunidades en la sociedad. Desde esta perspectiva, dado que las personas con discapacidad son titulares de los mismos derechos que el resto de la ciudadanía (ONU, 2006), la sociedad debería eliminar cualquier barrera que pueda obstaculizar el acceso a los recursos y servicios educativos, sociales, culturales, sanitarios, así como a los espacios de participación social, política y cultural.

Si aceptamos que la discapacidad es resultado de un proceso social, para su comprensión 
tendremos que prestar atención a muchas dimensiones que aparecerán relacionadas: el empleo, la participación social o las relaciones sociales. Una manera útil de acercarse a este análisis es a partir del consenso existente en la actualidad sobre exclusión social.

La exclusión social -como la discapacidadse reconoce como un fenómeno complejo, resultado de un cúmulo de factores, con un marcadísimo carácter transversal y, por tanto, presente también en el contexto en que se desenvuelven las personas con discapacidad. Al examinar las dimensiones en que se operativiza el concepto de exclusión social, y comparando la población con y sin discapacidad, hemos comprobado que las personas con discapacidad suelen aparecer como un colectivo que permanece en clara situación de discriminación.

La exclusión está estrechamente relacionada con la discriminación, es decir, con un trato desigual y negativo a aquellas personas que son distintas por motivos de su etnia o raza, identidad nacional, condición física o psíquica, orientación sexual, discapacidad, etc. La discapacidad es una de las causas de discriminación más extendidas en la sociedad actual, reconocida con frecuencia por casi medio millón de personas en España.

A pesar de que en las últimas décadas se ha llevado a cabo un trabajo considerable en materia de sensibilización y concienciación de la sociedad, los datos muestran, que la situación de invisibilización de la población con discapacidad persiste.

Las personas con discapacidad son discriminadas en el ámbito educativo y alcanzan inferiores niveles de estudios que el resto de la población; disponen de menos oportunidades para acceder al mercado de trabajo; hacen frente a restricciones extraordinarias para participar activamente en la sociedad, y desarrollar una vida afectiva y social normalizada.

El reconocimiento de que la discapacidad tiene un origen o explicación social pone el foco de atención en el entorno habitual de las personas con discapacidad. Entorno que es importante, según el modelo social, no sólo por los recursos de apoyo que puede disponer, sino por su influencia en la configuración de la propia discapacidad. Influencia que puede resultar liberadora, pero también opresora: "las interacciones de los miembros de la sociedad con las personas con discapacidad intelectual (y/o psiquiátrica) muchas veces son las que limitan la autonomía y el auto-concepto de estas personas" (Díaz, 20I0:I25).

El paradigma social de la discapacidad establece un equilibrio muy sensible entre el respeto a la autonomía individual y el diseño de recursos de apoyo destinados a la inclusión social. Este equilibrio sin duda está muy mediado por elementos de diversidad funcional. En este sentido, el papel de las instituciones -incluyendo en ellas la familia, los recursos públicos y privados de apoyo, los sistemas de protección económica, etc.- y su reorganización en base al criterio fundamental de la independencia personal, sitúan la disponibilidad de vínculos y redes sociales como elementos clave.

Las situaciones de confluencia entre exclusión y discapacidad requieren el despliegue de medidas específicas de intervención, que tengan en cuenta las situaciones de multi-exclusión. Para ello, será fundamental la introducción de la discapacidad como elemento transversal en las políticas de lucha contra la exclusión. En dicho enfoque, las políticas dirigidas a las personas con discapacidad deberían actuar sobre los entornos donde estas personas viven, para hacerlos accesibles y universales, reduciendo las barreras estructurales y simbólicas existentes.

Las personas con discapacidad que se encuentran en situación de exclusión precisan oportunidades especiales, adaptadas a necesidades específicas, basadas fundamentalmente en la promoción de autonomía personal con los apoyos que sea necesario.

La coordinación de los Servicios Sociales Públicos de diferente naturaleza -pública, privada, etc.-, rango administrativo -local, autonómico, etc.- o especialidad -inmigración, 
discapacidad, igualdad, etc.- se constituye como un elemento fundamental para evitar o atenuar las situaciones de exclusión en las personas con discapacidad.

La reducción de la discapacidad como factor de riesgo de exclusión social pasa por el establecimiento de recursos para el fortalecimiento de la autonomía personal, que permita una toma de control sobre las cuestiones que afectan a la propia vida. En la medida en que las personas con discapacidad encuentran un entorno que facilita su expresión y participación social, la invisibilidad de este grupo comienza a desaparecer. Igualmente, en la medida en que se incrementan las iniciativas de auto-representación de las personas con discapacidad, o crecen los desarrollos normativos vinculados a la perspectiva social de la discapacidad -como la Convención sobre los Derechos de las Personas con Discapacidad (CDPD)-, los grandes sistemas de apoyo organizados en base a diagnósticos médicos van perdiendo fortaleza simbólica.

En el terreno de las fuentes de información estadística, se requiere una atención diferente en cada operación, pero en todo caso tomando como referencia las previsiones de la Convención Internacional sobre los Derechos de las Personas con Discapacidad, que en su artículo 3 I dedicado a la "Recopilación de datos y estadísticas", dispone que "los Estados Partes recopilarán información adecuada, incluidos datos estadísticos y de investigación, que les permita formular y aplicar políticas, a fin de dar efecto a la presente Convención” (ONU, 2006). Resulta conveniente incluir de manera transversal la variable discapacidad, para lo cual se precisa delimitar su contenido conceptual, según sea pertinente en cada caso, con arreglo a lo indicado por la CDPD. A su vez, es conveniente considerar, la participación de las propias personas con discapacidad en el diseño y difusión de las estadísticas, evitando procedimientos discriminatorios. 
Anaut, S. y Álvarez, M.J. (2009): “El impacto de la crisis sobre los hogares con personas con discapacidad". En: El primer impacto de la crisis en la cohesión social en España. Madrid: Fundación FOESSA, 32, 2010: 221-260.

CERMI (2003): Discapacidad y exclusión social. Madrid: Cinca.

Díaz, E. (2010): “Ciudadanía, identidad y exclusión social de las personas con discapacidad". Revista Política y Sociedad, 47 (I): II 5-I35.

ENCUESTA SOCIAL EUROPEA (2010): [Online] $<$ http://www.upf.edu/ess/> acceso I 2 de enero de 2013 .

Fernández, C.I. (20I2): "La inteligencia emocional como estrategia educativa inclusiva". Innovación educativa, 2I, 20I I: I33-I 50

Ferreira, M.A.V. (2010): “De la minusvalía a la diversidad funcional: un nuevo marco teóricometodológico". Revista Política y Sociedad, 47 (I): 45-65

FOESSA (2008): VI Informe sobre exclusión $y$ desarrollo social en España. Madrid: Fundación FOESSA.

Huete, A. (2013): Pobreza y exclusión social de las mujeres con discapacidad en España. Madrid: Cinca.

Huete, A. y Quezada, M. (2012): La discapacidad en las fuentes estadísticas oficiales. Examen $y$ propuestas de mejora. Análisis formal y de contenido sobre discapacidad en las referencias del Instituto Nacional de Estadística (INE). Madrid: CINCA.

Huete, A. (20I0): "Propuesta de un sistema de indicadores de la inclusión social”. En Pérez Bueno, L.C.: Discapacidad, Tercer Sector e Inclusión Social. Madrid: CINCA.

Jiménez, A. y Huete, A. (20I0a): "Políticas públicas sobre discapacidad en España. Hacia una perspectiva basada en los derechos". Revista Política y Sociedad, 47 (I): I37-I 52.
Jiménez, A. y Huete, A. (20Iob): "Estadísticas y otros registros sobre discapacidad en España”. Revista Politica y Sociedad. (I): I 65-I73.

Jiménez, A. y Huete, A. (2003): Las discapacidades en España: Datos estadísticos. Aproximación desde la Encuesta sobre Discapacidades, Deficiencias y Estado de Salud I999. Madrid: Real Patronato sobre Discapacidad.

Laparra, M. et al. (2007): "Una propuesta de consenso sobre el concepto de exclusión social. Implicaciones metodológicas". Revista Española del Tercer Sector, 5: I 5-57.

Laparra, M. y Pérez B. (Coord.) (2008): Exclusión Social en España. Un espacio diverso y disperso en intensa transformación. Madrid: FOESSA, Colección Estudios $n^{\circ} 24$.

Lépore, E. (2006): Exclusión social: en busca de su especificidad conceptual. Ciudad Autónoma de Buenos Aires: Fundación Observatorio Social.

Ministerio de Sanidad y Política Social (2009): III Plan De Acción Para Las Personas Con Discapacidad 2009-20I2. Madrid: Ministerio de Sanidad y Política Social e IMSERSO (en línea). <http://sid.usal.es/idocs/F8/FDO2 I 595 / III_pacd.pdf $>$.

ONU (200I): World Population Prospects. New York: ONU.

ONU (2006): Convención sobre los Derechos de las Personas con Discapacidad. Nueva York: Organización de las Naciones Unidas.

Palacios, A. y Bariffi, F. (2007): La discapacidad como una cuestión de derechos humanos: una aproximación a la Convención Internacional sobre los Derechos de las Personas con Discapacidad. Madrid: CINCA

Renes, V. (2009): "Desarrollo social, pobreza y exclusión social”. En: Jaraíz, G. (Coord.): Actuar ante la exclusión. Análisis, políticas $y$ herramientas para la inclusión social. Madrid: FOESSA: 23-56, Colección Estudios n ${ }^{\circ} 29$. 
Sen, A. (2000): "Social Exclusion: concept, application, and scrutiny". Social Development Papers $\mathrm{N}^{\circ}$ I, Manila, Philippines: Asian Development Bank (en línea). <http:// housingforall.org/Social_exclusion.pdf $>$.

Subirats, J. (2005): Análisis de los factores de exclusión social. Bilbao: Fundación BBVA, documentos de trabajo 4 .

Subirats, J. (dir.) (2004): Pobreza y exclusión social. Un análisis de la realidad española y europea. Barcelona: La Caixa, Colección de Estudios Sociales, ${ }^{\circ}$ I 6.
Taylor-Gooby, P. (2003): "The impact of New Social Risks on welfare states". Comunicación presentada en la Conferencia de ESPAnet. Copenhague, $\mathrm{I} 3$ de noviembre de 2003 (en línea). <http://www.sfi.dk/graphics/ESPAnet/ papers/Taylorgooby.pdf>

Zaidi, A. y Burchardt, T. (2003): “Comparing incomes when needs differ: equivalisation for the extra costs of disability in the UK". Centre for Analysis of Social Exclusion Paper, $\mathrm{n}^{\circ}$ 64, febrero de 2003 . 